\title{
CREENCIASI Y COSTUMBRES TRADICIONALES \\ DEL PUEBLO INDÍGENA MÍSKITU DE KAHKABILA
}

\author{
Lina Carlos Grádiz[1] \\ Sonia Garth G] $^{[2]}$ \\ Tutora: Paula Ingram ${ }^{[3]}$
}

\section{Resumen}

El abordaje se hizo a partir de la investigación: "Creencias y costumbres tradicionales del pueblo indígena miskitu de la comunidad de Kahkabila" de Laguna de Perlas, Región Autónoma del Atlántico Sur de Nicaragua (RAAS). Se considera la revitalización un factor importante para el fortalecimiento de la identidad y autoestima del pueblo y por ende del desarrollo de la comunidad y la Educación Intercultural Bilingüe (EIB).

Para el análisis de la pérdida paulatina de las creencias y tradiciones ancestrales de esta comunidad miskitu, se identifican las causas y se proponen alternativas de solución que contribuyan a la sensibilización de la juventud. Se aplicaron entrevistas en la lengua miskitu a los adultos y ancianos; en kriol a los jóvenes, mujeres y varones. Se utilizó la observación, para así valorar la forma y estilo de vida de los comunitarios.

Se puede mencionar que los resultados de las principales causas de la pérdida de las creencias y costumbres tradicionales, es la emigración masiva de los miskitu de la comunidad de Kahkabila. La situación económica y la imitación del estilo de vida en otras etnias.

Las recomendaciones se basan en la revitalización cultural, Educación Intercultural Bilingüe, actitudes y prácticas tradicionales.

\section{Introducción}

La investigación "Creencias y costumbres tradicionales del pueblo indígena Miskitu de Kahkabila" se realiza en Kahkabila en un esfuerzo de revitalización de la cultura Miskitu en nuestra región.

Kahkabila es una comunidad ubicada a la orilla Oeste de Laguna de Perlas, Región Autónoma del Atlántico Sur de Nicaragua (RAAS). Dista a $8 \mathrm{~km}$ desde Laguna de Perlas y $42 \mathrm{~km}$ de Bluefields, cabecera regional. Debido a esta ubicación, sus pobladores han vivido tradicionalmente de la abundancia de los recursos naturales en la zona, principalmente la pesca.

[1] Lida. en Ciencias de la Educación con mención en Educación Intercultural Bilingüe.

[2] Lida. en Ciencias de la Educación con mención en Educación Intercultural Bilingüe.

[3] Máster en Antropología Social con mención en Desarrollo Humano. 
El nombre de Kahkabila se originó de unos árboles de palma, que en miskitu se llama Kahka. Como el lugar tenía muchos de estos árboles, los pobladores decidieron poner a la comunidad el nombre Kahkabila, que significa "Boca de Palma". Las familias vivían en una punta bastante extendida en la laguna, era más bien como un cabo. La comunidad de Kahkabila fue fundada por los señores Silvestre Joseph, su esposa Elizabeth Rigby, el señor Cristóbal Vega y su esposa, originarios de río Coco.

Se valora inmanente que la juventud valore sus creencias y costumbres tradicionales. Los comunitarios han perdido paulatinamente gran parte de estas creencias y costumbres, por lo que han adoptado otras, principalmente del pueblo creole.

La revitalización es de interés no sólo para los comunitarios, asimismo para las instituciones gubernamentales y no gubernamentales que trabajan con las diferentes comunidades de la Costa Caribe nicaragüense. Además, servirá como material educativo en la implementación del nuevo currículo de Educación Intercultural Bilingüe.

\section{Revisión de literatura}

Las referencias inmediatas en la apreciación de la cosmovisión y cultura del pueblo miskitu en general son consideradas en el libro de Avelino Cox, intitulado: Cosmovisión de los pueblos de Tulu Walpa (1998) y en la referencia mediata, el estudio de Eduard Conzemius, Estudio Etnográfico sobre los indios Miskitos y Sumus de Honduras y Nicaragua (1932).

La Constitución Política de Nicaragua en sus Artículos 5 y 8 reconoce la existencia de pueblos indígenas, quienes conforman la sociedad nacional y son parte activa de la naturaleza multiétnica del país. El Estatuto de Autonomía, Ley No. 28 ; ratifica estos conceptos para la Costa Caribe, desde 1987, destacándose así los conceptos de pueblos indígenas y comunidades étnicas.

La autonomía y, en particular, el Sistema Educativo Autonómico Regional (SEAR), parten del hecho de reconocer la diversidad cultural, étnica y social del pueblo costeño como realidad histórica del país.

Palabras claves: Creencias, Costumbres, cosmovisión, identidad cultural, mito, tradición, rito.

\section{Materiales y métodos}

Es una metodología participativa y cualitativa a través de la cual se identifican las creencias y costumbres y la pérdida de los mismos por el pueblo miskitu de Kahkabila. 
La población que participó directamente en las entrevistas está constituida por 46 personas de la comunidad, la cual se hizo de forma aleatoria, tomándose como criterio la equidad de género y edad. Los métodos utilizados fueron: entrevistas individuales, grupales a jóvenes, madres y padres de familia, ancianos, sukias, comadronas, pastores y síndico; asimismo la observación directa en la comunidad.

\section{Resultados y discusión}

La medicina tradicional es una de las costumbres y/o creencias de los pobladores de Kahkabila que se ha ido perdiendo. Antes se curaban algunas de las enfermedades más comunes de la siguiente manera:

Dolor de muela: Se pone a hervir la raíz del zacate grama (tuih) y se mantiene el agua tibia en la boca por tres minutos y se repite. Con este remedio se aliviaba el dolor.

Calentura: Se machucaba las hojas de malva (aras kanka o dinartangni) y se mezcla con jugo de limones, se baña la persona con el agua. La persona se queda curada sin necesidad de tomar pastilla.

Dolor de oído: Se cuecen las hojas de "kaisni pata" (sin traducción) y se pone unas gotas en el oído. Inmediatamente se le quita el dolor.

Dolor de cabeza: Se raya las hojas de tuna, se le echa un poquito de sal, se coloca en un pedazo de tela y luego se lo amarra sobre la cabeza. En seguida el dolor se va.

Diarrea: Se consigue 3 cocos pequeños, se parten cada uno en cuatro pedazos. Estos se cuecen con las cáscaras de marañón rojo y se toma el agua. Santo remedio.

Para no tener más hijos: Al dar a luz, las comadronas tomaban la placenta de la mujer lo ponían en la mitad de una calabaza nueva y lo enterraban boca abajo en la tierra y las mujeres jamás salían embarazadas.

Para Los niños de seis años en adelante que se orinaban en la cama: Se les curaba dándoles de tomar agua de la cáscara de huevo recién salido los pollitos, por seis días, de las diferentes cáscaras.

Cuando alguien padecía de los riñones o cuando se orinaba y le causaba molestia como ardor 0 dificultad de orinar (goteo): Se usaba el pelo del maíz el cual se hervía y se tomaba como agua del tiempo. En el período de tres días los enfermos eran curados.

Para los partos secos: las comadronas o parteras conseguían la malva, la machucaban en una panita de agua, hasta que se ponía alaste, se echaba a esta mezcla seis gotas 


\section{CULTURA INDÍGENA Y AFRODESCENDIENTE}

de agua florida, cada media hora le daban medio vasito de tomar y salían rápido del parto.

Para la anemia o palidez en la persona: se le daban la cuculmeca (Dusa pauni) se le hervía hasta que el agua se ponía roja, lo tomaba como té, con o sin azúcar. Este remedio se tomaba por un mes.

En relación a la división del trabajo, las mujeres compartían las labores del campo con sus maridos, limpiaban el patio, ayudaban en la siembra, etc. También era una tarea de las mujeres, triar el arroz en granza. Para ello, usaban unu, que es un palo con hueco (Pilón), y otro palo redondo para triar el arroz o sea pilar. Así mismo, las mujeres eran las que cargaban el saco de bastimento, y a veces leña en sus hombros, mientras el hombre caminaba detrás solamente con un palo en mano o su machete. Al regresar a sus chozas el hombre se acostaba en su hamaca, mientras la mujer seguía normal con sus quehaceres del hogar. Esto era una tradición en todas las comunidades indígenas.

Las mujeres cuando estaban con su menstruación no podían cocinar para sus esposos o hijos varones, porque esto le daba ahogamiento. Al igual no podían asistir a misa, porque no estaban limpias para estar en presencia de Dios, por tanto, se les obligaba a confesar ante los líderes religiosos.

También era costumbre "Cuando las niñas reglaban por primera vez, la gente adulta las llevaban a los líderes religiosos para una confesión para así confirmar que no estuvieron con hombres" (Poblador de la comunidad de Kahkabila, 2009).

Por la menstruación a las mujeres se les negaba el derecho a estudiar y en el caso de que salieran embarazadas, eran aisladas de las demás jovencitas. De igual manera, para la siembra, participaban mayormente mujeres, pero si estaban con la menstruación no podían ni acercarse al lugar, porque esto podría traer infertilidad de los productos.

Las niñas no tenían derecho de aprender a leer ni escribir, esto era cosa de hombres. Las niñas aprendían a hacer las tareas del hogar junto con sus madres... Cuando una joven salía embarazada, la apartaban de las otras muchachas jóvenes porque esto era un gran pecado y esto podría traer una maldición en las otras jóvenes si se mezclaban con la embarazada (Pobladora de la comunidad de Kahkabila, 2009).

En la comunidad indígena de Kahkabila, antes del profeta Florentin Joseph, doña Meriana era la primera sukia. Esta señora vivía sola al lado de un caño y podía predecir las enfermedades. Cantaba y hacía sus rituales antes de atender a la gente, luego les decía si podía ayudarlos. También era capaz de determinar que el padecimiento de la persona era brujería (Uplamunan) o bien si era una enfermedad natural. 
Asimismo, se usaba una hoja especial para hacer sus escobas (papta wahya), y así recomendaba mantener sus casas limpias. Entre otras cosas, los sukias, cuando los niños nacían con velo, preparaban un amuleto el cual lo juntaba con kuakua mah, usus mah., porque si no, estas niñas y niños eran perseguidos por espíritus.

Según la cosmovisión por la luna y el sol, los miskitus de la comunidad de Kahkabila trabajaban con el cambio de la luna para sus siembras, cortar madera, para hacer sus cayucos. De igual manera, para cortar las hojas de palma, para la construcción de su vivienda y para la caza de algunos animales.

En la comunidad de Kahkabila, las costumbres funerarias consistían en que se enterraba al muerto junto con todas sus pertenencias (azagaya, lanza, comida, etc.) Esto demostraba la esperanza en que sus muertos se inmortalizaran a través de sus espíritus. Era algo muy sagrado, de esta manera el cementerio se mantenía lleno de las pertenencias de los difuntos.

Posteriormente al entierro, durante los nueve días, los familiares de la persona muerta, debían de llorar los nueve días sin cesar, especialmente en horas de la madrugada, como si fuera el primer día de muerte. De igual manera, debían de poner un vaso de agua en el cuarto o el lugar donde estaba el difunto, por lo que según la creencia, el espíritu del muerto llega a la casa de la familiar buscando agua. Al finalizar o bien llegar al noveno día, al amanecer o antes de salir el sol, recogían la ropa de cama del difunto y la llevaban al cementerio. En el cementerio, sacudían esta ropa encima de la tumba, la cual era de tierra. Este ritual se realizaba para que el espíritu del muerto no se quedara penando en la casa.

En relación a los animales, los pobladores de Kahkabila eran observadores de las hormigas. Esto debido a que dichos animales les servían de guía. Por tanto, cuando esos animales cambiaban de un lugar a otro con sus huevos, era un indicador de que se esperaba una situación alarmante, principalmente vinculado a la presencia de fenómenos naturales como tormentas, huracanes, llenas, etc. A partir de este comportamiento de las hormigas, los pobladores de esta comunidad cambiaban las pajas de sus chozas, reforzando las paredes con tablones, bambúes y bejucos nuevos, de tal manera que fueran más fuertes y pudieran soportar cualquier fenómeno natural que se presentara.

Durante la Semana Santa los miskitus no comían carne de ningún tipo, preparaban su pescado seco meses atrás y lo guardaban. Para la Semana Mayor no hacían ninguna actividad como pescar, cazar, cortar leña, ni ir a su finca. Sólo asistían a sus actividades religiosas, debido a que estos días eran sagrados para ellos.

El principal medio de transporte para la comunidad de Kahkabila era el duri (cayuco), el cual se construía con algunos árboles especiales llamados Saba, Yulu, Sum, 
que son cedro macho, caoba, laurel, Santa María, el barbéchele y el banak o árbol de cebo. Este constituía un instrumento básico de comunicación, así como para llevar a cabo la pesca. Los cayucos con quilla eran usados en las lagunas y en el mar (llamada "duri"), los cuales eran de fondo grueso y plano, en cambio el "Pipante" era utilizado para navegar en los ríos.

Según los ancianos, las armas que se construían se utilizaban para defenderse, las cuales se denominan trisbaya (flechas).

También se construían objetos como cuchillos y raspadores a partir de la concha, los huevos, caparazones de la tortuga y dientes de animales con el propósito de ser utilizados para la pesca y la caza de animales. Estos huesos de animales, así como el cuarzo y el pedernal, los utilizaban para construir lanzas, anzuelos, puntas de flechas para capturar grandes peces de agua dulce; arpones para capturar grandes peces, tortugas y manatíes. Una vez que se capturaba un manatí, los hombres usaban una de las costillas del manatí para afeitarse y cortarse sus vellos.

Por otro lado, los arpones tenían algunas diferencias de acuerdo con el tipo de pez que se quería capturar. Con estos se mataban toda clase de animales, hasta peces; que luego se cocinaban con leche de coco. El coco se rayaba con cuchillo, porque no conocían el rayador, para colar usaban komfra (colador), que era un material que se secaba de un árbol, con las palmas de ese mismo árbol de komfra forraban sus casas.

Uno de las costumbres miskitas, era la cacería, se programaba con anticipación, porque en ella participaban muchos hombres de la comunidad, especialmente durante la cacería del manatí, que es uno de las más importantes costumbres de la comunidad. Para cazar a este animal, los hombres de la comunidad tuvieron que preparar sus materiales de caza, tales como su cayuco, arpón con su mecate, candil (putash), etc. Esta preparación fue debido a que esos animales son grandes y los hombres tenían que tomar sus precauciones. Esto lo hacían en parejas. Los hombres salían en la madrugada, a esta hora los manatíes se alimentaban. Durante el mes de mayo, el agua de la laguna se pone salada, así que cuando los animales se mueven, el agua echa como chispa debido a la magnitud de sal que contiene, y esto hace más fácil que los cazadores se den cuenta donde están agrupados los manatíes.

La técnica para capturar manatíes era compleja; la realizaban por lo general dos hombres en su cayuco. Mientras uno de ellos timoneaba el cayuco, el otro arponeaba la presa y ambos remaban y tiraban de la cuerda, cuyo garfio había quedado clavado en el animal, hasta que finalmente lo capturaban.

Cada pareja sólo podía cazar uno, debido al tamaño de los animales. El más pequeño que cazaban pesaba como trescientas libras. Si las cinco canaletas tenían la suerte de matar a un animal lo hacían, pero no todas las veces tenían la suerte de que en cada 
canaleta mataban un animal. Cuando regresaban a la comunidad era una gran fiesta, repartían la carne con los comunitarios, con la población entera. Si mataban más de uno, entonces un grupo de hombres llevaba la carne a las comunidades vecinas como Set Net Point y Tasbapauni. Hacían trueques, porque cambiaban la carne de manatí por coco, carne de tortuga y aceite de coco.

Los hombres cocinaban la cabeza del manatí en la mitad de un barril, la cocinaban en pura agua y la llamaban luk luk (boil up). Las mujeres no participaban en esta actividad, porque era prohibido que ellas comieran la cabeza del manatí. Según la creencia esto podía causar la desaparición absoluta de los animales y traer mala suerte a los cazadores. Sólo los hombres, jóvenes y niños varones podían comer de la cabeza del manatí.

En Kahkabila hay un lugar especial donde hay mayor concentración de los manatíes. En este lugar hay una piedra que tiene forma de la cabeza de un manatí. Cuando llega la manada de manatí la piedra se da vuelta sola, con su cara directamente al Este donde están las manadas de manatí, y al pasar la temporada de manatí la piedra se vuelve su cara nuevamente al Oeste. El lugar donde se encuentra la piedra se llama Yalapou. Este lugar se encuentra entre dos caños, que se llaman Pihtutingni y el otro Pinskutban.

La gente preparaba las carnes y pescado para guardarlos y esperar el temporal que se avecinaba. Tenían una forma especial de prepararlos para que se conservaran o mantuvieran sanos, envolviéndolos en hojas llamadas huaja (bijahua), que son las hojas que actualmente se usan para envolver el nacatamal.

Para cocinar usaban el fogón (pauta-wihta o kubus). Esto se hacía de palo y tierra de una forma cuadrada con cuatro patas. Echaban bastante tierra, en la superficie, la cual tenía que ser plana. Según la cantidad de familia en el hogar, así era el tamaño del fogón. Para mantenerlo limpio se lavaba con la ceniza de la leña y en vez de la tierra roja se mantenía blanca, debido a la ceniza producida.

Como bastimento usaban el buña hecha de yuca. Cocinaban la yuca, la machucaban, no echaban sal, la envolvían en hojas de huaja. Las hojas las mantenían frescas, y al día siguiente lo comían.

En relación a las bebidas alcohólicas se sacaba de la caña de azúcar, por lo que hacían la chicha de caña y cususa. También cortaban un árbol de palma llamado sila. Después de cortar el árbol hacían un hoyo dejándolo por tres días y regresaban para sacar la savia o el jugo que salía del árbol, lo cual se convertía en una bebida tan fuerte como cualquier whisky. 
Una de sus bebidas especiales era uhum. Es una semilla similar a la palma africana, se cocinaban las semillas y después las machucaban sacándole el jugo, agregaban miel de caña y lo tomaban como fresco. De igual manera el wabul, hecha de la yuca (yawhra) y la patata dulce era una de las bebidas típicas, para ello, tanto la yuca como la patata dulce la cocinaban, después la machucaban y se agregaba la leche de coco y miel de caña.

Cuando iban a su finca a trabajar no llevaban agua de sus casas, usaban un bejuco especial (llamada liana), que al cortarlo salía agua fresca para tomar. Este bejuco crece entre los árboles grandes en el bosque a la orilla del camino donde tienen que pasar.

Para la fabricación de sus ropas, la gente usaba la cáscara del tuno, la echaban en agua tibia primero, después la enfriaban y machucaban. El producto se usaba en la fabricación de ropas y sábanas. Hombres y mujeres lo usaban especialmente para su ropa interior ya que volvía en un material muy suave. A esta se les decía palpura. Cortaban el material de forma triangular lo cual cubría sus partes íntimas.

Los hombres fabricaban sus fajas y sandalias del cuero del danto. A las mujeres no les era permitido usar sandalias, chinelas, mucho menos zapatos, tenían que permanecer descalzas.

Sus instrumentos musicales eran kumbi y tramp tramp. El kumbi era un tambor: lo cortaban de un palo especial en forma de media luna, para cubrirlo usaban el cuero de venado 'encima' y con esto se tocaba cualquier música. El tramp tramp eran dos palos en forma de serrucho. Lo jalaban de una forma suave para sacarle las diferentes melodías de sus cantos.

Las personas mayores manifestaron que la pérdida de las creencias y costumbres tradicionales de los miskitus de la comunidad de Kahkabila, se debe a la guerra que hubo en los años ochenta en la Costa Caribe nicaragüense. Durante los años ochenta los comunitarios indígenas de Kahkabila, aún practicaban sus creencias y costumbres tradicionales o ancestrales. Usaban su lengua materna miskitu; hubo pocos comunitarios que podían hablar el kriol. En el año 1985, se produjo una migración masiva de la comunidad por la guerra entre el Frente Sandinista y los contrarrevolucionarios. Para el año 1986, esta comunidad indígena estaba despoblada: no quedaba nadie en la comunidad, sólo los militares, quienes controlaban toda la comunidad.

Además, la situación económica tenía mucha influencia. Originalmente la población de Kahkabila solo dependió de la pesca y la agricultura. Sin embargo, después de la guerra la situación económica en las comunidades indígenas era muy mala: la gente ya no podía regresar a sus comunidades y quedarse, así que el proceso de inmigración siguió su curso. Por tanto, estas mujeres y hombres al regresar a sus comunidades traían nuevas creencias y costumbres que adoptaron de otros pueblos. 
Los jóvenes miskitus también optaron por irse al extranjero, especialmente para trabajar de 'embarcados' en los cruceros del Caribe, de igual manera los jóvenes creoles. Estos cuando regresaban de sus trabajos en los Estados Unidos u otros países, ya no querían las chocitas de paja, sino casas de concreto, de allí comenzó el gran cambio en esta comunidad indígena de Kahkabila.

En relación a las actitudes y a las prácticas tradicionales, se puede mencionar que muchas costumbres todavía se practican en la comunidad; empero, la población joven es la que tiene los mayores rechazos.

Los jóvenes -mujeres y varones-, reconocen las creencias y costumbres tradicionales por los relatos de sus abuelos, madres, padres, tíos, tías y hasta sus vecinos mayores. El hecho de que estos jóvenes tenga un nivel de conocimiento sobre ello, es un indicador de que tanto los mitos, cuentos, leyendas, creencias y costumbres tradicionales están latentes en la comunidad.

Proponen que sería bueno hacer proyectos con el objeto de revitalizar estas creencias y costumbres, pero no están de acuerdo de practicarlas todos. Porque para ellos, practicar algunas de estas creencias sería como regresar a "la edad de piedra". Por otro lado, también se discutió con los jóvenes la situación del pueblo creole, quienes en su mayoría concluyeron que se sienten bien y seguros viviendo de las costumbres y creencias de esta etnia. "Nosotros los jóvenes estamos conscientes de que estamos usando las creencias y costumbres de la etnia creole, pero como jóvenes nos sentimos más seguros" (Joven de la comunidad de Kahkabila, 2009).

Para algunos jóvenes, el sentirse bien está ligado al idioma, debido que para ellos es mejor hablar el kriol que el miskitu, ya que en la mayoría de las comunidades vecinas la gente habla el kriol. Contrario a esto, otros, mencionaron que hablando el miskitu, ellos se sienten orgullosos, porque no todos pueden hablar o comunicarse en esta lengua y eso define mucho su identidad.

También las madres y padres de familia que entrevistamos expresaron que los jóvenes no aceptan estas creencias y costumbres, que para ellos suena como algo fantasioso. En la comunidad se ha perdido todo, los cuentos en las noches de luna desaparecieron, todos optaron por la televisión.

Durante las visitas a la comunidad de Kahkabila en los diferentes lugares públicos y privados, pudimos observar que la mayoría de los jóvenes lleva una vida distinta a la vida tradicional de este pueblo étnico. Si no fuera por sus características físicas uno no podía hacer la distinción entre jóvenes creoles. Sus vestuarios ya no son como antes: visten con jeans en su mayoría, en ambos sexos. Su música favorita es el reggae o reggaeton. 
Sin embargo, los más adultos llevan una vida calma: son tímidos a la hora de conversar con uno, no son tan abiertos; pero sí creen en sus creencias tradicionales y añoran retomar algunas de sus costumbres ancestrales aunque al hablar de esto, los jóvenes están a la defensiva repudiando las costumbres que se practicaban.

Incluso algunas madres y padres de familia se sienten culpables de esta situación. Piensan que ellos tienen la culpa de no inculcarles a sus hijos estas creencias y costumbres a temprana edad.

Llegamos a la conclusión de que los más afectados en todos estos son las personas ancianas. Estas personas piensan que esta nueva generación le falta el respeto a sus antepasados. Sus opiniones las manifestaron en su lengua materna que es el miskitu. Comentaban que nada ni nadie va a hacer que hablen en otras lenguas.

También pudimos observar que dos de los viejitos andaban con su sombrero de paja bien elaborado, hechos por ellos mismos.

\section{Conclusiones}

La comunidad de Kahkabila, al igual que las otras comunidades indígenas posee sus propias cosmovisiones, cuenta de sucesos extraordinarios que han sucedido en estas comunidades y que siguen siendo relatados por los mayores, pero que han venido perdiendo paulatinamente la mayoría de sus creencias y costumbres tradicionales.

Entre estos factores hay características comunes entre mujeres y hombres: migración de su comunidad y la situación económica que experimentaron en los años ochenta, producto de la guerra que hubo en la Costa Caribe nicaragüense. No tuvo otra opción, sino emigrar de su comunidad para mejorar la situación de sus familiares.

\section{Listas de referencias}

Conzemius, Eduard (1932). Estudio Etnográfico sobre los indios miskitos y sumus de Honduras y Nicaragua. Asociación Libro Libre, San José.

Cox, Avelino (1998). Cosmovisión de los pueblos de Tulu Walpa. URACCAN, Bilwi.

República de Nicaragua (1987). Estatuto de Autonomía. Managua, Nicaragua.

Rizo Mario (2003). Cultura. $1^{\circ}$ edición. Terra Nuova, Managua.

Quintana Caballas, José María (2001). Las Creencias y la Educación, Pedagogía. 
Cosmovisional Barcelona. Pp. 193-194.

Ember Carol \& Ember Melvin (1997). Antropología Cultural. 8va. Ed. Prentice Hall, Madrid. 